\title{
Modification of skin composition by conjugated linoleic acid alone or with combination of other fatty acids in mice
}

\author{
Daichi Oikawa ${ }^{1}$, Tomonori Nakanishi ${ }^{1}$, Yoshi-nori Nakamura ${ }^{1}$, Takaya Yamamoto ${ }^{2}$, Atsuko Yamaguchi ${ }^{2}$, \\ Nobuya Shiba $^{3}$, Hisao Iwamoto ${ }^{1}$, Tetsuya Tachibana ${ }^{1}$ and Mitsuhiro Furuse ${ }^{1} *$ \\ ${ }^{1}$ Laboratory of Advanced Animal and Marine Bioresources, Graduate School of Bioresources and Bioenvironmental Sciences, \\ Kyushu University, Fukuoka 812-8581, Japan \\ ${ }^{2}$ Rinoru Oil Mills Co. Ltd, Nagoya 455-0028, Japan \\ ${ }^{3}$ National Agricultural Research Center for Kyusyu Okinawa Region, Nishigoshi 861-1192, Japan
}

(Received 27 December 2004 - Revised 13 March 2005 - Accepted 18 March 2005)

The effects of conjugated linoleic acid (CLA), $\gamma$-linolenic acid (GLA), linoleic acid (LA), and their combinations, on skin composition in mice were investigated. Mice ( 8 weeks old) were orally administered with either LA, GLA, CLA, LA + GLA, LA + CLA, or CLA + GLA for 4 weeks. Then, the skin was analysed for triacylglycerol content, fatty acid composition and collagen content. Additionally, thicknesses of the dermis layer and subcutaneous tissue layer, and the size and number of adipocytes were measured histologically. The skin fatty acid composition was modified depending upon the fatty acid composition of supplemented oils. In each oil-alone group, skin triacylglycerol content was the highest in LA, followed by GLA and CLA treatments. Combinations with CLA had a similar triacylglycerol content compared with the CLA-alone group. No significant changes in collagen content were observed among any treatments. The effects on subcutaneous thickness were similar to the results obtained in the triacylglycerol contents, where groups supplemented with CLA alone or other fatty acids had significantly thinner subcutaneous tissue compared with the LA-alone group. However, no significant difference was detected in the thickness of the dermis layers. The number of adipocytes was highest in the LA + GLA group and tended to be reduced by CLA with or without the other fatty acids. These results suggest that CLA alone or in combination with other fatty acids strongly modifies skin composition in mice.

Conjugated linoleic acid: $\gamma$-Linolenic acid: Subcutaneous tissue

The skin has an important role in protecting the animal from the external influences including bacteria, UV radiation, etc. (Boelsma et al. 2001). The skin is divided into three layers including the epidermis, dermis, and subcutaneous tissue. The dermis includes collagen and elastin, and is associated with elasticity and flexibility of the skin. The subcutaneous tissue (hypodermis) accumulates fat as adipocytes. The subcutaneous blood flow is related to the thickness of the subcutaneous tissue layer or total body fat mass (Girolamo et al. 1971; Nielsen \& Larsen, 1973). Obese subjects accumulate subcutaneous adipose tissues and have a higher subcutaneous blood pressure (Landin et al. 1989; Jansson et al. 1992), and have a greater risk for CVD (Lapidus et al. 1984; Larsson et al. 1984).

Skin function and attractiveness are greatly altered by nutritional conditions. For instance, ingested fatty acids influence skin composition (Boelsma et al. 2001). Long-chain n-6 and $n-3$ PUFA are considered essential fatty acids. These PUFA are metabolised by elongases and desaturases. In $n-6$ PUFA, linoleic acid (LA) is metabolised to $\gamma$-linolenic acid (GLA), dihomo$\gamma$-linolenic acid (DGLA), and to prostaglandin (PG) E1 or arachidonic acid (AA). Eicosanoids derived from AA, such as $\mathrm{PGE}_{2}$ and leucotriene $\mathrm{B} 4$, are involved in inflammation and can alter the allergic response in the skin (Horrobin, 2000; James et al.
2000). The importance of LA is confirmed by deficiency, since ingestion of a fat-free diet induced cornification of skin lesions in rats (Sinclair, 1990). This suggests that LA is an important factor in maintaining healthy skin. On the other hand, although LA is rich in the skin (Oikawa et al. 2003), excessive LA causes inflammation and allergic responses in various organs including the skin (Gleich \& Kita, 1997; Fogh \& Kragballe, 2000).

Evening primrose oil, blackcurrant-seed oil and borage oil are rich in GLA. Supplementation of these plant oils has been reported to increase GLA and DGLA levels in the epidermis and erythrocyte membrane because GLA is metabolised to DGLA by elongase (Brosche \& Platt, 2000; Chung et al. 2002). These compositional changes alter skin barrier function and decrease transepidermal water loss in elderly individuals (Brosche \& Platt, 2000). Additionally, GLA has anti-inflammatory and immunomodulating effects (Wu et al. 1999; Chung et al. 2002). $\mathrm{PGE}_{1}$ or 15-hydroxyeicosatrienoic acid is produced from DGLA by cyclo-oxygenase or 15-lipoxygenase. $\mathrm{PGE}_{1}$ and 15-hydroxyeicosatrienoic acid inhibit leucotrienes, which act as pro-inflammatory mediators (Ziboh et al. 2000).

Conjugated linoleic acid (CLA) is the generic term representing positional and geometrical isomers of LA, and is included mainly 
in food items produced from ruminant animals. CLA was reported to decrease epididymal white adipose tissue weight, mesenteric adipose depots, and adipocytes in the subcutaneous tissue (Nakanishi et al. 2001; Oikawa et al. 2003). CLA also blocks the metabolism from LA to GLA in $n$-6 PUFA (Bretillon et al. 1999; Tsuboyama-Kasaoka et al. 2000). As a result, AA and $\mathrm{PGE}_{2}$ levels are reduced in some tissues (Belury, 2002). Furthermore, CLA inhibits the growth of cancer cells and induces apoptosis in the liver and adipose tissue (Belury, 2002). In addition, ingested CLA easily transfers to the skin (Oikawa et al. 2003), and was reported to affect allergic pruritus in mice (Ishiguro et al. 2002). CLA seems to be beneficial for skin composition. However, CLA increases the weight of the liver in mice (Tsuboyama-Kasaoka et al. 2000; Nakanishi et al. 2004). On the other hand, Nakanishi et al. (2004) reported that the combination of CLA and GLA prevented fatty liver induced by CLA. This combination, as well as CLA alone, had an anti-obesity effect on visceral fat (Nakanishi et al. 2004). So far, however, no available information on the mixture of CLA and GLA for skin composition has been reported. The purpose of the present study was to investigate the effect of the combination of CLA and LA or GLA on skin composition in mice compared with CLA, GLA or LA alone.

\section{Materials and methods}

\section{Animals and treatments}

Male mice ( 8 weeks old, Sea:ddY strain; Seac Yoshitomi, Ltd, Fukuoka, Japan), were kept at $24^{\circ} \mathrm{C}$ on a $12 \mathrm{~h}$ dark-12 h light cycle, housed individually, and had free access to a commercial diet (MF; Oriental Yeast Co. Ltd, Tokyo, Japan) and water. Food intake was monitored individually by using clean animal feeding equipment (Type M; Rodent Cafe, Oriental Yeast Co. Ltd, Tokyo, Japan). The chemical composition (\%) of the commercial diet was moisture $6 \cdot 9$, crude protein $23 \cdot 9$, crude fat $5 \cdot 4$, crude ash $6 \cdot 1$, crude fibre 3.0 and $\mathrm{N}$-free extract $54 \cdot 7$, respectively. The mice were divided into six groups of five mice each according to their body weights.

Mice were orally administered $250 \mu$ l of the LA, GLA, or CLA oil source per $\mathrm{d}$ for 4 weeks, respectively, by using $1 \mathrm{ml}$ syringes attached with tubes. The remaining three groups were administered a combination of each oil source; these were the LA + GLA, LA + CLA and CLA + GLA groups. These groups receiving the combinations were given $250 \mu$ l of each oil (total $500 \mu \mathrm{l}$ ) every day for 4 weeks. The LA group served as the control, and was given high-LA safflower-seed oil (triacylglycerol-type; Rinoru Oil Mills Co. Ltd, Nagoya, Japan) which contained $71.8 \%$ LA. The GLA group was given an oil containing $95.0 \%$ GLA (free fatty acid-type; Idemitsu Technofine Co. Ltd, Tokyo, Japan). The CLA group was given an oil containing 70.8\% CLA (triacylglycerol-type; Rinoru Oil Mills Co. Ltd, Nagoya, Japan) that contained $32.4 \%$ of $9 \mathrm{cis}$, 11trans-CLA and $33.3 \%$ of 10trans, 12cis-CLA. The fatty acid composition of these oils is shown in Table 1. The LA content of the safflower-seed oil was $158.2 \mathrm{mg}$ in $250 \mu \mathrm{l}$. The GLA content of the ethyl GLA oil was $198.5 \mathrm{mg}$ in $250 \mu \mathrm{l}$, and the CLA content was $143.7 \mathrm{mg}$ in $250 \mu$ l. The amounts (mg) of CLA-isomers were: 9cis, 11trans (65.8); 10trans, 12cis (67.4); 9cis, 11cis (2.4); 10cis, 12cis (2.2); 9trans, 11trans +10 trans, 12trans (5.9), respectively. The experimental procedures followed the guidance for Animal
Table 1. Compositions of experimental oils (\% of total fatty acids)

\begin{tabular}{lccr}
\hline & LA & GLA & CLA \\
\hline $16: 0$ & $6 \cdot 5$ & - & $6 \cdot 6$ \\
$18: 0$ & $2 \cdot 5$ & - & $2 \cdot 4$ \\
$18: 1$ & $17 \cdot 1$ & - & $16 \cdot 6$ \\
$18: 2 n-6$ & $71 \cdot 8$ & - & $1 \cdot 5$ \\
CLA & - & - & $70 \cdot 8$ \\
9cis, 11trans- & - & - & $32 \cdot 4$ \\
10trans, 12cis- & - & - & $33 \cdot 2$ \\
cis, cis- & - & - & $2 \cdot 3$ \\
trans, trans- & - & - & $2 \cdot 9$ \\
$18: 3 n-6$ & - & $95 \cdot 0$ & - \\
Others & $2 \cdot 1$ & $5 \cdot 0$ & $2 \cdot 1$ \\
\hline
\end{tabular}

LA, linoleic acid; GLA, $\gamma$-linolenic acid; CLA, conjugated linoleic acid.

Experiments in the Faculty of Agriculture and in the Graduate Course of Kyushu University and the Law (no. 105) and Notification (no. 6) of the Japanese Government.

\section{Collection of skin tissues}

At the conclusion of the experiment, mice were killed by diethyl ether anaesthesia. Then, their whole skin (with hair) was removed. Skin sheets $(1 \mathrm{~cm} \times 1 \mathrm{~cm})$ were cut from the back of all mice for histology. Half of the remaining skin was used for collagen analysis and the other half was used for fatty acid analysis. After weighing, the skin was kept at $-80^{\circ} \mathrm{C}$ until analysis.

\section{Determination of collagen content}

Skin samples were ground with a mill (Millser700G; Iwatani Co., Tokyo, Japan), and fragmentised in $10 \mathrm{ml} 0.15 \mathrm{M}-\mathrm{NaCl}$ for $1 \mathrm{~h}$ with ultrasound. The collagen content was determined according to the modified method by Bergman \& Loxley (1963). Briefly, $20 \mathrm{ml} 6 \mathrm{M}-\mathrm{HCl}$ was added, and the suspension hydrolysed for $24 \mathrm{~h}$ at $20^{\circ} \mathrm{C}$, and kept for $10 \mathrm{~h}$ at $120^{\circ} \mathrm{C}$ with a block heater (ALB-121; Asahi Technoglass Co. Ltd, Tokyo, Japan). The hydrolysed sample was filtered and adjusted to $100 \mathrm{ml}$ with distilled water. The sample $(1 \mathrm{ml})$ was evaporated with a centrifugal evaporator (CVE-3100; Eyela Co., Tokyo, Japan). Evaporated samples were diluted with distilled water. A $0.2 \mathrm{ml}$ sample was mixed with $0.4 \mathrm{ml}$ isopropanol, followed by mixing with $0.2 \mathrm{ml}$ oxidant solution ( $75 \%$ (w/v) chloramine $\mathrm{T}$ and acetate-citrate buffer ( $\mathrm{pH}$ 6.0) were mixed at a ratio of 3:1). The mixed sample solution was kept for $4 \mathrm{~min}$ at room temperature $\left(17\right.$ to $\left.20^{\circ} \mathrm{C}\right)$. After adding $2.6 \mathrm{ml} \mathrm{Ehr-}$ lich's reagent solution, the sample was incubated at $60^{\circ} \mathrm{C}$ for $25 \mathrm{~min}$. After cooling with water for 2 to $3 \mathrm{~min}$, the sample solution was diluted with $6.6 \mathrm{ml}$ isopropanol. The hydroxyproline concentration in the sample solution was determined using a spectrophotometer at $560 \mathrm{~nm}$.

\section{Determination of triacylglycerol content}

The skin was ground with a mill (Millser700G; Iwatani Co., Tokyo, Japan). Total lipid was extracted using a modified Folch method (Folch et al. 1957; Seya et al. 2000). A chloroformmethanol $(2: 1, \mathrm{v} / \mathrm{v})$ solution was added to the skin sample, and homogenised in a centrifugal tube. The mixture was centrifuged 
for $10 \mathrm{~min}$ at $850 \mathrm{~g}$ to separate into two distinct phases, and the lower phase was collected. The chloroform-methanol solution was again added to the upper phase followed by homogenisation and centrifugation. Both fractions were filtered and mixed with a $\mathrm{KCl}$ solution $(0.9 \%, \mathrm{w} / \mathrm{v})$. After $5 \mathrm{~min}$, the samples were centrifuged at $1250 \mathrm{~g}$ for $10 \mathrm{~min}$. The lower phase was diluted to $20 \mathrm{ml}$ with chloroform, and a $250 \mu \mathrm{l}$ sample was placed in a microtube, evaporated, and then assayed using a triacylglycerol determination kit (Triglyceride-Wako; Wako Co., Osaka, Japan). The remaining diluted solution $(5 \mathrm{ml})$ was placed in a screw-cap glass vial and evaporated. Air in the screw-cap glass vial was replaced by gaseous $\mathrm{N}_{2}$, and the resulting extracts were stored at $-80^{\circ} \mathrm{C}$ until fatty acid analysis.

\section{Fatty acid analysis}

Determination of fatty acid composition was done using GC (HP5890II; Hewlett Packard Co., Palo Alto, CA, USA) after transmethylation in $14 \%$ methanolic $\mathrm{BF}_{3}$ (Kamegai et al. 2001). The GC was equipped with a J\&W DB-23 fused (50\%-Cyanopropyl)methylpolysiloxane capillary column $(30 \mathrm{~m} \times 0.25 \mathrm{~mm}$ internal diameter, $0.25 \mu \mathrm{m}$ film thickness; Agilent Technologies Inc., Palo Alto, CA, USA). The carrier gas used was $\mathrm{He}$ at a flow of $100 \mathrm{kPa}$. The oven was programmed from $160^{\circ} \mathrm{C}$ to $220^{\circ} \mathrm{C}$ at $2^{\circ} \mathrm{C} / \mathrm{min}$, and the injector and detector temperatures were set at $250^{\circ} \mathrm{C}$.

\section{Observation of skin histology}

The skin samples were processed following a conventional procedure (Ohtani et al. 1988). Specimens were fixed in $3 \%$ glutaraldehyde diluted with phosphate buffer $(\mathrm{pH} 7 \cdot 5)$ at $4^{\circ} \mathrm{C}$. The fixed samples were soaked in $10 \% \mathrm{NaOH}$ for $4 \mathrm{~d}$ and then in distilled water for $3 \mathrm{~d}$. Samples were immersed in $1 \%$ tannic acid for $2 \mathrm{~h}$, and then soaked in a $2 \%$ osmium tetroxide solution for $1 \mathrm{~h}$. Skin samples were dehydrated through a graded series of ethanol washes. Specimens were placed in $t$-butyl alcohol and freezedried (TIS-U-DRY; FIS Systems, International Co., New York, NY, USA). Samples were laid on Al holders and coated with Pt-Pd (Eiko IB-3 Ion Coater; Eiko Co., Kobe, Japan) and examined under an ss-550 scanning electron microscope (Shimadzu Co., Kyoto, Japan) at the Center of Advanced Instrumental Analysis, Kyushu University. The thickness of the dermis layer and subcutaneous tissue layer between the dermis layer and fascia on the photomicrograph were measured.

\section{Measurements of adipocyte size and number}

The skin samples were fixed in $3 \%$ glutaraldehyde diluted with phosphate buffer $(\mathrm{pH} 7.5)$ at $4^{\circ} \mathrm{C}$. The sample was immersed in $1 \%$ tannic acid for $0.5 \mathrm{~h}$ and soaked in a $1 \%$ osmium tetroxide solution for $1 \mathrm{~h}$. Skin samples were dehydrated through a graded series of ethanol washes. Specimens were placed in $t$-butyl alcohol and freeze-dried (TIS-U-DRY; FIS Systems, International Co., New York, NY, USA). Samples were laid on Al holders and coated with Pt-Pd (Eiko IB-3 Ion Coater; Eiko Co., Kobe, Japan), and examined under an ss-550 scanning electron microscope (Shimadzu Co., Kyoto, Japan) at the Center of Advanced Instrumental Analysis, Kyushu University. The cell size and number of the adipocytes in the subcutaneous tissue layer were measured. The adipocyte size was determined by the average of major and minor axis of the adipocyte. The numbers of adipocytes with diameters more than $10 \mu \mathrm{m}$ were counted in $1 \mathrm{~mm}^{2}$ and divided into groups with $20 \mu \mathrm{m}$ intervals.

\section{Statistical methods}

Data were statistically analysed by one-way ANOVA. When significant effects were found, the six dietary groups were compared by Fisher's Protected Least Significant Difference test and Tukey-Kramer's test. Statistical significant difference was set at $P<0.05$. The results are shown as means with their standard errors.

\section{Results}

Fig. 1 shows the effect of CLA, GLA or LA, and their combination, on skin triacylglycerol content in mice. Comparisons among the individual oil groups indicated that the triacylglycerol content was highest for LA treatment followed by GLA, then CLA. When combined with LA and GLA, the triacylglycerol content was similar to the GLA-alone group rather than the LA-alone group. Triacylglycerol contents in the LA + CLA or CLA + GLA groups were comparable with the CLA-alone group. The collagen content in the fresh skin $(\mathrm{mg} / \mathrm{g})$ was not significantly different among groups (LA 123 (SEM 9), GLA 122 (SEM 3), CLA 142 (SEM 10), LA + GLA 123 (SEM 9), LA + CLA 131 (SEM 5), CLA + GLA 149 (SEM 11)).

The effect of several oils and their combination on fatty acid composition of the skin is shown in Table 2. The amount of LA, GLA and CLA was modified by the administered oils. The LA content in the LA-alone, LA + GLA and LA + CLA groups was more than $33 \%$, and the remaining three groups contained less than $28 \%$ LA. The GLA content was higher in the groups combining GLA with other fatty acids compared with the GLA-alone group. However, the CLA content was higher in the CLA-alone group than in the groups combining CLA with other fatty acids. In the CLA oil group, the isomer of 9cis,

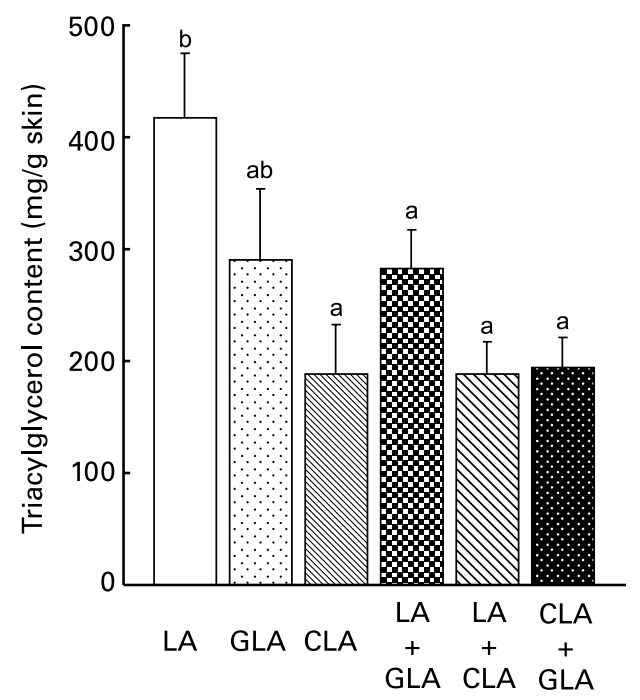

Fig. 1. Triacylglycerol content in the skin of mice administered linoleic acid (LA), $y$-linolenic acid (GLA), conjugated linoleic acid (CLA) or their combinations. Values are means for five mice per group, with vertical bars representing the standard errors of the mean. ${ }^{a, b}$ Mean values with unlike letters were significantly different $(P<0.05)$. For details of diets and procedures, see Table 1 and p. 275. 
Table 2. Fatty acid compositions (\%) of total skin (five rats per group)*

(Mean values with their standard errors)

\begin{tabular}{|c|c|c|c|c|c|c|c|c|c|c|c|c|}
\hline \multirow{2}{*}{$\begin{array}{l}\text { Group... } \\
\text { Oil }\end{array}$} & \multicolumn{2}{|c|}{ LA } & \multicolumn{2}{|c|}{ GLA } & \multicolumn{2}{|c|}{ CLA } & \multicolumn{2}{|c|}{$\mathrm{LA}+\mathrm{GLA}$} & \multicolumn{2}{|c|}{$L A+C L A$} & \multicolumn{2}{|c|}{$\mathrm{CLA}+\mathrm{GLA}$} \\
\hline & Mean & SEM & Mean & SEM & Mean & SEM & Mean & SEM & Mean & SEM & Mean & SEM \\
\hline $14: 0$ & $1 \cdot 17^{\mathrm{a}}$ & 0.07 & $1 \cdot 71^{\mathrm{b}}$ & 0.37 & $0.83^{\mathrm{a}}$ & $0 \cdot 13^{a}$ & $1.02^{\mathrm{a}}$ & 0.06 & $0.74^{a}$ & 0.02 & $1.05^{\mathrm{a}}$ & 0.08 \\
\hline $16: 0$ & $18 \cdot 78^{\mathrm{b}}$ & 0.65 & $20.72^{\mathrm{c}}$ & 0.80 & $20.56^{c}$ & $0.60^{c}$ & $17.54^{\mathrm{a}}$ & 0.37 & $18 \cdot 10^{\mathrm{b}, \mathrm{c}}$ & 0.40 & $19 \cdot 41^{a, b}$ & 0.63 \\
\hline $16: 1$ & $4 \cdot 41^{b, c}$ & 0.40 & $5 \cdot 84^{c}$ & 0.71 & $2 \cdot 28^{a}$ & $0.59^{a}$ & $4 \cdot 13^{b}$ & 0.44 & $2 \cdot 45^{\mathrm{a}}$ & 0.66 & $2 \cdot 42^{\mathrm{a}}$ & 0.16 \\
\hline $18: 0$ & $2 \cdot 60^{\mathrm{a}}$ & 0.16 & $3 \cdot 29^{a, b}$ & 0.44 & $4 \cdot 31^{c}$ & $0.27^{c}$ & $2 \cdot 84^{a}$ & 0.10 & $3 \cdot 89^{b, c}$ & 0.14 & $3 \cdot 81^{b, c}$ & 0.26 \\
\hline $18: 1$ & $31.77^{\mathrm{b}}$ & 0.64 & $31 \cdot 10^{a, b}$ & 0.53 & $34 \cdot 14^{\mathrm{c}}$ & $0.56^{c}$ & $29 \cdot 15^{a}$ & 0.54 & $30 \cdot 86^{a, b}$ & 1.03 & $29 \cdot 36^{a}$ & 0.69 \\
\hline CLA & $0.50^{\mathrm{a}}$ & 0.07 & $0.49^{\mathrm{a}}$ & 0.13 & $8 \cdot 11^{\mathrm{c}}$ & $0.63^{c}$ & $0.56^{\mathrm{a}}$ & 0.14 & $5 \cdot 29^{b}$ & 0.36 & $6 \cdot 98^{c}$ & 0.80 \\
\hline $9 \mathrm{cis}, 11$ trans & $0.29^{a}$ & 0.04 & $0.27^{a}$ & 0.07 & $4 \cdot 71^{d}$ & $0.37^{d}$ & $0.32^{\mathrm{a}}$ & 0.08 & $3.02^{b}$ & 0.19 & $3 \cdot 84^{c}$ & 0.42 \\
\hline 10trans, $12 \mathrm{cis}$ & $0.13^{a}$ & 0.02 & $0 \cdot 13^{\mathrm{a}}$ & 0.05 & $2 \cdot 77^{c}$ & $0.25^{c}$ & $0.09^{a}$ & 0.04 & $1 \cdot 78^{\mathrm{b}}$ & 0.16 & $2 \cdot 53^{c}$ & 0.33 \\
\hline cis, cis & $0.01^{a}$ & 0.01 & $0.03^{a, b}$ & 0.01 & $0.28^{d}$ & $0.02^{d}$ & $0.08^{b}$ & 0.03 & $0.20^{c}$ & 0.01 & $0.27^{d}$ & 0.03 \\
\hline trans, trans & $0.08^{a}$ & 0.01 & $0.05^{\mathrm{a}}$ & 0.00 & $0.35^{\mathrm{b}}$ & $0.01^{b}$ & $0.06^{a}$ & 0.01 & $0.29^{b}$ & 0.02 & $0.33^{b}$ & 0.04 \\
\hline $18: 3 n-6$ & $0.37^{a}$ & 0.17 & $2.99^{b}$ & 0.31 & $0.23^{a}$ & $0.09^{a}$ & $4.72^{\mathrm{c}}$ & 0.56 & $0.42^{\mathrm{a}}$ & 0.21 & $4.50^{c}$ & 0.52 \\
\hline $18: 3 n-3$ & $1.05^{c}$ & 0.06 & $1 \cdot 14^{c}$ & 0.04 & $0.63^{\mathrm{a}}$ & $0 \cdot 10^{\mathrm{a}}$ & $1.03^{\mathrm{c}}$ & 0.08 & $0.57^{\mathrm{a}}$ & 0.04 & $0.84^{b}$ & 0.06 \\
\hline $20: 3$ & $0.23^{a}$ & 0.04 & $0.51^{\mathrm{c}, \mathrm{d}}$ & 0.05 & $0.42^{b, c}$ & $0 \cdot 12^{b, c}$ & $0.67^{\mathrm{d}, \mathrm{e}}$ & 0.04 & $0.31^{a, b}$ & 0.05 & $0.83^{\mathrm{e}}$ & 0.01 \\
\hline Saturated & $23 \cdot 1$ & 0.62 & $27 \cdot 0$ & $1 \cdot 10$ & $27 \cdot 1$ & 1.02 & $22 \cdot 0$ & 0.49 & 23.8 & 0.34 & $25 \cdot 9$ & 0.70 \\
\hline Unsaturated & 76.9 & 0.62 & 73.0 & $1 \cdot 10$ & 72.9 & 1.02 & $78 \cdot 0$ & 0.49 & $76 \cdot 2$ & 0.34 & $74 \cdot 1$ & 0.70 \\
\hline
\end{tabular}

LA, linoleic acid; GLA, $\gamma$-linolenic acid; CLA, conjugated linoleic acid.

$\mathrm{a}, \mathrm{b}, \mathrm{c}, \mathrm{d}, \mathrm{e}$ Mean values within a row with unlike superscript letters were significantly different $(P<0.05)$.

${ }^{*}$ For details of diets and procedures, see Table 1 and p. 275.

11trans-CLA was higher than that of 10trans, 12cis-CLA. No significant effect was detected in AA content among groups.

Fig. 2 shows representative scanning electron microscopic photographs of the dermis and subcutaneous layers of mice administered LA, GLA, CLA, or their combinations. The thickness of the dermis layer was not significantly $(F(5,24) 0 \cdot 245 ; P>0.05)$ different among the groups. The values $(\mu \mathrm{m})$ of this layer were 399 (SEM 15) for the LA treatment, 419 (SEM 41) for GLA, 424 (SEM 25) for CLA, 424 (SEM 21) for LA + GLA, 435 (SEM 23) for LA + CLA and 431 (SEM 20) for CLA + GLA, respectively. On the other hand, the thickness of subcutaneous tissues was significantly $(F(5,24) 5 \cdot 171 ; P=0.002)$ different among the groups (Fig. 3). The LA group was significantly thicker than the other groups. The subcutaneous layer of the LA + CLA group was the thinnest among treatment groups.

Fig. 4 (a) shows a representative sample of a scanning electron microscopic of the subcutaneous tissue layer. Fig. 4 (b) shows the total number of adipocytes in subcutaneous tissue with the number of adipocytes classified into $20 \mu \mathrm{m}$ intervals. The number of adipocytes in the subcutaneous tissue was highest in the LA + GLA group.

\section{Discussion}

The CLA oil used in the present study consisted mainly of 9 cis, 11trans-CLA (32.4\%) and 10trans, 12cis-CLA (33.2\%). However, the tissue content of 9cis, 11trans-CLA was 1.7 times higher than that of 10trans, 12cis-CLA in the CLA group (Table 2). This result was in agreement with the previous report (Oikawa et al. 2003). Even when combined with other fatty acids, the composition of 9cis, 11trans-CLA was 1.7 times and 1.5 times higher than that of 10trans, 12cis-CLA in the LA + CLA group and the CLA + GLA group, respectively. Without CLA administration, the mouse skin contained small amounts of several isomers of CLA, and the composition of 9cis, 11trans-CLA was 2.2-3.6 times higher than that of 10trans,
12cis-CLA. These results suggest that CLA is a naturally occurring fatty acid, and 9cis, 11trans-CLA is easily transferred into the skin, but the rate of transfer between 9cis, 11trans-CLA and 10trans, 12cis-CLA may be altered by the combination of specific fatty acids. Since individual CLA isomers were not given in the present study, it was not clear which isomers caused the reduction in triacylglycerol content and the decrease in the thickness of the subcutaneous layer in the skin. Brown et al. (2001) reported that the 10trans, 12cis-CLA isomer inhibited accumulation of fat in the body, since the isomer played a role in the inhibition of hepatic stearoyl-CoA desaturase activity (Park et al. 2000) and affected lipoprotein lipase activity (Lin et al. 2001). Taken together, the reduction in triacylglycerol content and the decrease in the thickness of the subcutaneous layer in the skin may be caused by 10trans, 12cis-CLA rather than 9cis, 11trans-CLA.

CLA has several beneficial effects; one of which is the inhibition of accumulation of visceral fat (Tsuboyama-Kasaoka et al. 2000; Nakanishi et al. 2001). In contrast, excessive CLA intake induces fatty liver in mice (Nakanishi et al. 2004). Nakanishi et al. (2004) reported that the combination of GLA and CLA ameliorated the fatty liver induced by CLA. In the present study, total doses of fatty acids in the combination groups were twice as much as those receiving single fatty acids. However, the CLA + GLA and CLA + LA groups had clearly reduced triacylglycerol content in total skin and thickness of the subcutaneous tissue compared with LA-alone group (Figs. 1 and 3). Additionally, since these results were similar to those obtained in the CLA-alone group, CLA was effective even when given in combination with other oils.

The composition of GLA was increased in the LA + GLA group and the CLA + GLA group compared with the GLAalone group. In the LA + GLA group, the enhancement of GLA came from metabolism of LA to GLA, but the reason for the increase of GLA in the CLA + GLA group compared with the GLA-alone group was unclear. The metabolism of GLA may be modified by CLA; however, we are not aware of any 
(a)

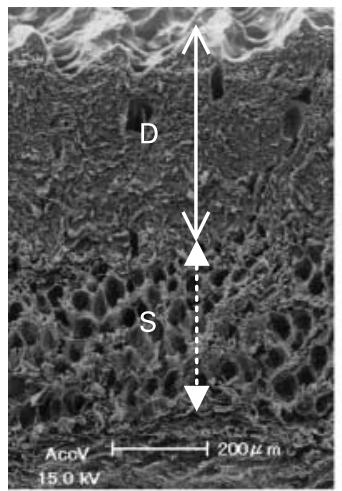

(d)

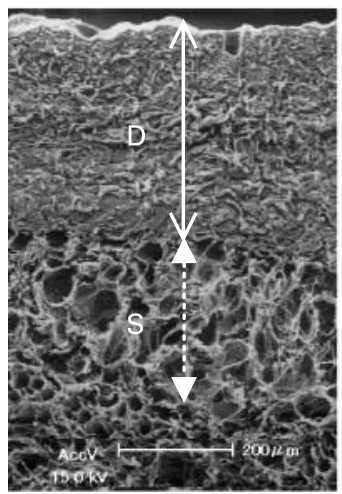

(b)

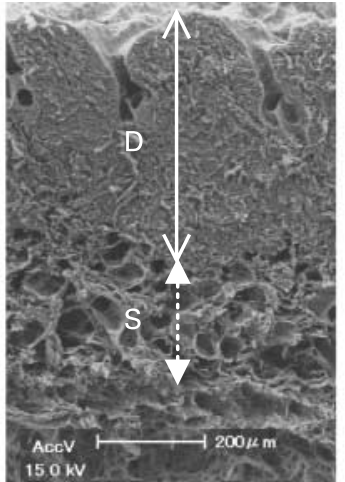

(e)

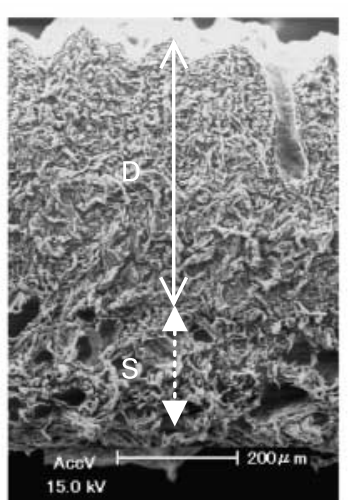

(c)

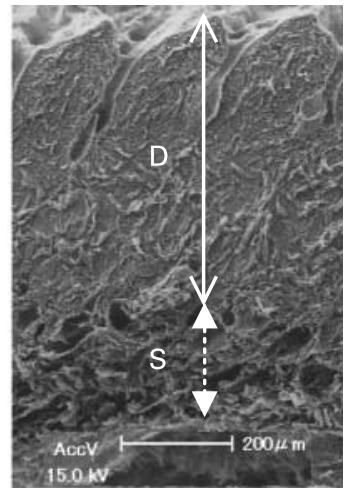

(f)

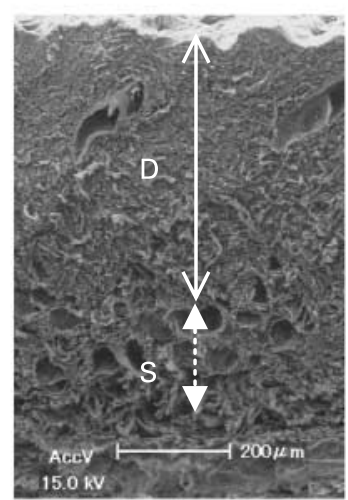

Fig. 2. Representative scanning electron microscopic photographs of the dermis (D) and the subcutaneous (S) tissue layers of mice administered linoleic acid (LA; (a)), $\gamma$-linolenic acid (GLA; (b)), conjugated linoleic acid (CLA; (c)), LA + GLA (d), LA + CLA (e) or CLA + GLA (f). Bars indicate 200 um. For details of diets and procedures, see Table 1 and p. 275.

work in this area. The reduction in triacylglycerol content reflects GLA composition in the CLA + GLA group (Fig. 1 and Table 2). The triacylglycerol content of the total skin tended to be lower in

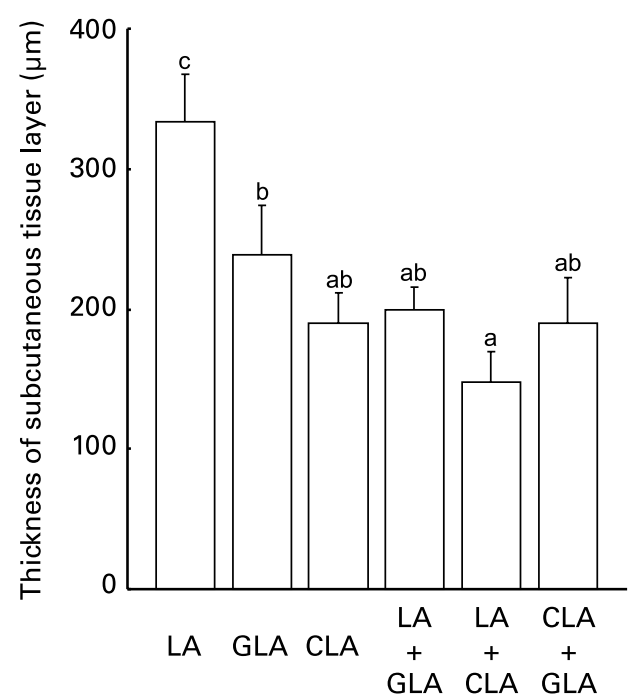

Fig. 3. Thickness of the subcutaneous layer of mice administered linoleic acid (LA), $\gamma$-linolenic acid (GLA), conjugated linoleic acid (CLA) or their combinations. Values are means for five mice per group, with vertical bars representing the standard errors of the mean. ${ }^{\mathrm{a}, \mathrm{b}, \mathrm{c}}$ Mean values with unlike letters were significantly different $(P<0.05)$. For details of diets and procedures, see Table 1 and p. 275. the GLA than LA group (Fig. 1). Furthermore, the thickness of the subcutaneous tissue was significantly thinner in the GLA than LA group (Fig. 3). GLA-enriched oil reduced white adipose tissue compared with LA-enriched oil because carnitine palmitoyltransferase and peroxisomal $\beta$-oxidation activities were increased by the GLA treatments (Takada et al. 1994; Takahashi et al. 2000).

The number of adipocytes in the LA + GLA group was about twice that of the LA or GLA groups (Fig. 4 (b)). The triacylglycerol content of the LA + GLA group tended to be higher than other mixture-oil groups. This suggests that higher triacylglycerol content was related to an increase in the number of adipocytes.

It was reported that $\mathrm{PGE}_{2}$ enhanced collagen synthesis (LeviSchaffer et al. 1995), and $\mathrm{PGE}_{1}$ inhibited collagenase gene expression in human cultured fibroblasts (Salvatori et al. 1992). Although the amounts of prostaglandins were not analysed in the present study, CLA appears to decrease their contents based on a previous report (Belury, 2002). However, the thickness of the dermis layer and collagen content were not significantly different among the six groups. These results were supported by our previous report (Oikawa et al. 2003). The difference may be explained by the method used; the present study was done in vivo, oils were administered orally and doses of the oils used did not induce excessive production of collagen (for example, keloid).

Dietary LA is easily transferred into the skin (Table 2; Oikawa et al. 2003). Excessive LA intake induced inflammation of the skin (Gleich \& Kita, 1997; Fogh \& Kragballe, 2000), because 
(a)

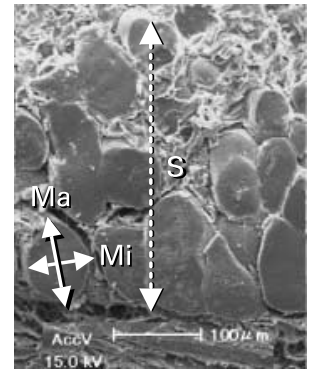

(b)

Adipocyte diameter $(\mu \mathrm{m})$

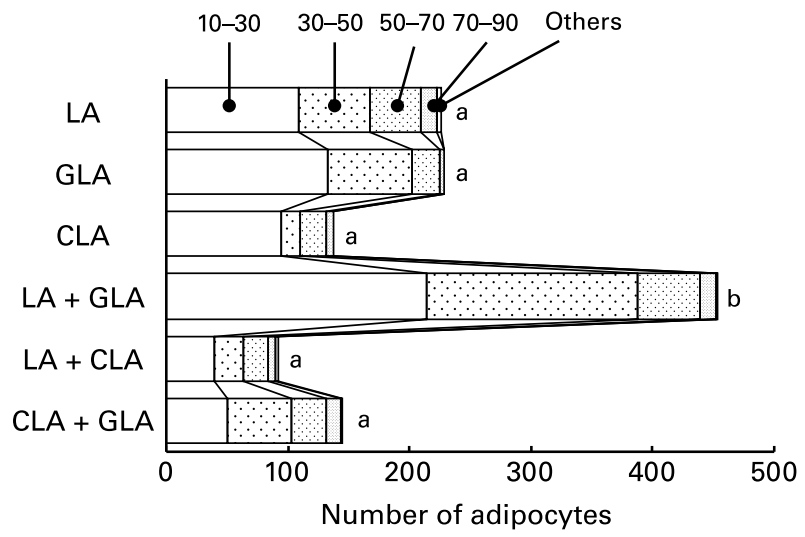

Fig. 4. (a) Representative scanning electron microscopic photographs of the subcutaneous tissue layer (S) of mice. Ma, major axis, Mi, minor axis. Bars indicate $100 \mu \mathrm{m}$. (b) Total number of adipocytes with different sizes in the subcutaneous tissue of mice administered linoleic acid (LA), $\gamma$-linolenic acid (GLA), conjugated linoleic acid (CLA) or their combinations. Values are means for five mice per group. ${ }^{a, b}$ Mean values with unlike letters were significantly different $(P<0.05)$. For details of diets and procedures, see Table 1 and p. 275.

LA was a primary source of chemical mediators such as $\mathrm{PGE}_{2}$ and leucotriene B4 via AA. It was reported that these eicosanoids stimulated pain or itch responses in the skin (Andoh \& Kuraishi, 1998; Kabashima et al. 2003). The amounts of fatty acids or lipids in the skin may have an important role for dermatitis and dehydration. Horrobin (2000) described that atopic eczema is caused by not only deficiency of essential fatty acids, but also by administration of excessive LA. The skin lesions of dietary essential fatty acids deficiency in human patients can be readily corrected by daily LA doses in the $0.5-3.0 \mathrm{~g}$ range, while excessive LA is required to reduce intake of LA and correct the ratio of LA to the downstream PUFA (Horrobin, 2000). On the other hand, increased GLA and DGLA composition in the epidermis improved skin barrier function and decrease transepidermal water loss in elderly individuals (Brosche \& Platt, 2000). The combination of CLA and other fatty acids may have a beneficial effect on the skin health. Although amounts of eicosanoids in the skin were not analysed in the present study, CLA (5-8\%) were included in the skin of the CLA-alone group and CLA with other fatty acids groups. Dietary CLA may reduce $\mathrm{PGE}_{2}$ or leucotriene B4 in the skin, since CLA blocks the desaturation of LA (Kavanaugh et al. 1999; Belury, 2002), release of AA from phospholipids, and production of eicosanoids from AA (Urquhart $e$ al. 2002). However, since CLA modulates production of eicosanoids histotypically (Belury, 2002), the eicosanoid contents remain to be studied in another experiment.
In conclusion, dietary CLA altered the fatty acid composition of the skin, triacylglycerol content, thickness of subcutaneous tissue, and the number and size of adipocytes. Additionally, these effects of CLA can be similarly seen when CLA was coadministered with other fatty acids. Therefore, it is suggested that CLA alone, or a mixture of CLA with GLA or LA, serve to improve the condition of the skin. For instance, CLA may reduce the subcutaneous adipose tissue in obese subjects, and then may induce a lower subcutaneous blood pressure. The best supplementation among the six groups may be dependent upon the skin and body conditions. For instance, CLA + GLA may regulate skin composition (present study) and prevent fatty liver (Nakanishi et al. 2004) in the obese.

\section{Acknowledgements}

The present study was supported by the Cosmetology Research Foundation, Tokyo, Japan. The authors are grateful to Dr D. M. Denbow, Virginia Polytechnic Institute and State University, USA, for his reading of the manuscript.

\section{References}

Andoh T \& Kuraishi Y (1998) Intradermal leukotriene $B_{4}$, but not prostaglandin $\mathrm{E}_{2}$, induces itch-associated responses in mice. Eur J Pharmacol 353, 93-96.

Belury MA (2002) Dietary conjugated linoleic acid in health: physiological effects and mechanisms of action. Annu Rev Nutr 22, 505-531.

Bergman I \& Loxley R (1963) Two improved and simplified methods for the spectrophotometric determination of hydroxyproline. Anal Chem 35, 1961-1965.

Boelsma E, Hendriks FJH \& Roza L (2001) Nutritional skin care: health effects of micronutrients and fatty acids. Am J Clin Nutr 73, 853-864.

Bretillon L, Chardigny JM, Gregoire S, Berdeaux O \& Sebedio JL (1999) Effects of conjugated linoleic acid isomers on the hepatic microsomal desaturation activities in vitro. Lipids 34, 965-969.

Brosche T \& Platt D (2000) Effect of borage oil consumption on fatty acid metabolism, transepidermal water loss and skin parameters in elderly people. Arch Gerontol Geriatr 30, 139-150.

Brown JM, Halvorsen YD, Lea-Currie YR, Geigerman C \& McIntosh M (2001) Trans-10, cis-12, but not cis-9, trans-11, conjugated linoleic acid attenuates lipogenesis in primary cultures of stromal vascular cells from human adipose tissue. J Nutr 131, 2316-2321.

Chung S, Kong S, Seong K \& Cho Y (2002) Gamma-linolenic acid in borage oil reverses epidermal hyperproliferation in guinea pigs. $J$ Nutr 132, 3090-3097.

Fogh K \& Kragballe K (2000) Eicosanoids in inflammatory skin diseases. Prostaglandins Other Lipid Mediat 63, 43-54.

Folch J, Lees M \& Stanley GHS (1957) A simple method for the isolation and purification of total lipides from animal tissues. J Biol Chem 226, 497-509.

Girolamo MD, Skinner NS, Hanley HG \& Sachs RG (1971) Relationship of adipose tissue blood flow to fat cell size number. Am J Physiol 220, 932-937.

Gleich GJ \& Kita H (1997) Bronchial asthma: lessons from murine models. Proc Natl Acad Sci U S A 94, 2101-2102.

Horrobin DF (2000) Essential fatty acid metabolism and its modification in atopic eczema. Am J Clin Nutr 71, Suppl., 367S-372S.

Ishiguro K, Oku H, Suitani A \& Yamamoto Y (2002) Effects of conjugated linoleic acid on anaphylaxis and allergic pruritus. Biol Pharm Bull 25, 1655-1657. 
James MJ, Gibson RA \& Cleland LG (2000) Dietary polyunsaturated fatty acids and inflammatory mediator production. Am J Clin Nutr 71, Suppl., 343S-348S.

Jansson PA, Larsson A, Smith U \& Lönnroth P (1992) Glycerol production in subcutaneous adipose tissue in lean and obese humans. $J$ Clin Invest 89, 1610-1617.

Kabashima K, Sakata D, Nagamachi M, Miyachi Y, Inaba K \& Narumiya $S$ (2003) Prostaglandin $E_{2}$-EP4 signaling initiates skin immune responses by promoting migration and maturation of langerhans cells. Nat Med 9, 744-749.

Kamegai T, Kasai M \& Ikeda I (2001) Improved method for preparation of the methyl ester of conjugated linoleic acid. J Oleo Sci 50, 237-241.

Kavanaugh CJ, Liu KL \& Belury MA (1999) Effect of dietary conjugated linoleic acid on phorbol ester-induced PGE2 production and hyperplasia in mouse epidermis. Nutr Cancer 33, 132-138.

Landin K, Krotkiewski M \& Smith U (1989) Importance of obesity for the metabolic abnormalities associated with an abdominal fat distribution. Metab Clin Exp 38, 572-576.

Lapidus L, Bengtsson C, Larsson B, Pennert K, Rybo E \& Sjöström L (1984) Distribution of adipose tissue and risk of cardiovascular disease and death: a 12-year follow-up of participants in the population study of women in Gothenburg, Sweden. Br Med J 289, 1257-1261.

Larsson B, Svärdsudd K, Welin L, Wilhelmsen L, Björntorp P \& Tibblin G (1984) Abdominal adipose tissue distribution, obesity, and risk of cardiovascular disease and death: 13 year follow-up of participants in the study of men born in 1913. Br Med J 288, 1401-1404.

Levi-Schaffer F, Baram D, Segal V, Garbuzenko E, Lew S \& Mekori YA (1995) Prostaglandin $E_{2}$ production by chronic graft-versus-host disease dermal fibroblasts. Immunol Lett 48, 11-15.

Lin Y, Kreeft A, Schuurbiers JAE \& Draijer R (2001) Different effects of conjugated linoleic acid isomers on lipoprotein lipase activity in 3T3L1 adipocytes. J Nutr Biochem 12, 183-189.

Nakanishi T, Ohgushi A, Yamashita T, Sashihara K, Takagi T, Dobashi E, Kamegai T, Kasai M, Yoshimatsu T \& Furuse M (2001) Effect of orally administered conjugated linoleic acids on behaviors and tissue fatty acid compositions in mice. J Appl Anim Res 20, 157-170.

Nakanishi T, Oikawa D, Koutoku T, Hirakawa H, Kido Y, Tachibana T \& Furuse M (2004) Gamma-linolenic acid prevents conjugated linoleic acid-induced fatty liver in mice. Nutrition 20, 390-393.

Nielsen SL \& Larsen OA (1973) Relationship of subcutaneous adipose tissue blood flow to thickness of subcutaneous tissue and total body fat mass. Scand J Clin Lab Invest 31, 383-388.
Ohtani O, Ushiki T, Taguchi T \& Kikuta A (1988) Collagen fibrillar networks as skeletal frameworks: a demonstration by cell-maceration/ scanning electron microscope method. Arch Histol Cytol 51, 249-261.

Oikawa D, Nakanishi T, Nakamura Y, et al. (2003) Dietary CLA and DHA modify skin properties in mice. Lipids 38, 609-614.

Park Y, Storkson JM, Ntambi JM, Cook ME, Sih CJ \& Pariza MW (2000) Inhibition of hepatic stearoyl-CoA desaturase activity by trans-10,cis12 conjugated linoleic acid and its derivatives. Biochim Biophys Acta 1486, 285-292.

Salvatori R, Guidon PT Jr, Rapuano BE \& Bockman RS (1992) Prostaglandin $\mathrm{E}_{1}$ inhibits collagenase gene expression in rabbit synoviocytes and human fibroblasts. Endocrinology 131, 21-28.

Seya K, Ohkohchi N, Shibuya H, Satoh M, Oikawa K, Fukumori T, Satomi S \& Motomura S (2000) A chemiluminescent assay for hydroperoxide level of phosphatidylcholine hydroperoxide fraction purified by two Sep-Pak cartridges in biological samples. J Pharm Biomed Anal 23, 515-520.

Sinclair HM (1990) History of essential fatty acids. In Omega-6 Essential Fatty Acids: Pathophysiology and Roles in Clinical Medicine, pp. 1-20 [DF Horrobin, editor]. New York: Alan R Liss Inc.

Takada R, Saitoh M \& Mori T (1994) Dietary gamma-linolenic acidenriched oil reduces body fat content and induces liver enzyme activities relating to fatty acid beta-oxidation in rats. J Nutr 124, 469-474.

Takahashi Y, Ide T \& Fujita H (2000) Dietary gamma-linolenic acid in the form of borage oil causes less body fat accumulation accompanying an increase in uncoupling protein $1 \mathrm{mRNA}$ level in brown adipose tissue. Comp Biochem Physiol 127, 213-222.

Tsuboyama-Kasaoka N, Takahashi M, Tanemura K, Kim HJ, Tange T, Okuyama H, Kasai M, Ikemoto S \& Ezaki O (2000) Conjugated linoleic acid supplementation reduces adipose tissue by apoptosis and develops lipodystrophy in mice. Diabetes 49, 1534-1542.

Urquhart P, Parkin SM, Rogers JS, Bosley JA \& Nicolaou A (2002) The effect of conjugated linoleic acid on arachidonic acid metabolism and eicosanoid production in human saphenous vein endothelial cells. Biochim Biophys Acta 1580, 150-160.

Wu D, Meydani M, Leka LS, Nightingale Z, Handelman GJ, Blumberg JB \& Meydani SN (1999) Effect of dietary supplementation with black currant seed oil on the immune response of healthy elderly subjects. Am J Clin Nutr 70, 536-543.

Ziboh VA, Miller CC \& Cho Y (2000) Metabolism of polyunsaturated fatty acids by skin epidermal enzymes: generation of antiinflammatory and antiproliferative metabolites. Am J Clin Nutr 71, Suppl., 361S-366S. 